\title{
Comparison of the Therapeutic Outcomes between Open Plantar Fascia Release and Percutaneous Radiofrequency Ablation in the Treatment of Intractable Plantar Fasciitis
}

\author{
Yusong Yuan \\ Peking University People's Hospital \\ Yuan Qian \\ The Affiliated Hospital of Qingdao University \\ Hao Lu \\ Peking University People's Hospital \\ Yuhui Kou \\ Peking University People's Hospital \\ Yangbo Xu \\ Affiliated Hospital of Southwest Medical University \\ Hailin Xu ( $\square$ xuhailinfa@163.com ) \\ Peking University People's Hospital https://orcid.org/0000-0003-1829-3852
}

Research article

Keywords: intractable plantar fasciitis, open plantar fascia release, percutaneous radiofrequency ablation

Posted Date: January 8th, 2020

DOI: https://doi.org/10.21203/rs.2.20318/v1

License: (c) (i) This work is licensed under a Creative Commons Attribution 4.0 International License.

Read Full License

Version of Record: A version of this preprint was published at Journal of Orthopaedic Surgery and Research on February 18th, 2020. See the published version at https://doi.org/10.1186/s13018-0201582-2. 


\section{Abstract}

B ackground : Heel pain is one of the most common complaints in foot and ankle clinic and one of the leading causes of heel pain is plantar fasciitis.

Methods : A retrospective analysis was carried out in 31 cases (39 feet) of patients with intractable plantar fasciitis. In the enrolled 26 cases, there were 16 patients (19 feet) received open plantar fascia release, and the other 15 patients (20 feet) received percutaneous radiofrequency ablation. The surgical results were assessed by visual analogue scale (VAS) and American orthopaedic foot and ankle society ankle-hindfoot scale (AOFAS-AH) before and after surgery in all patients.

Results: All 31 patients were followed up successfully, with a mean follow-up time of 58.77 months. There were no differences of patient's demographics and characteristics information between the two groups. The average operative time of the feet in the open plantar fascia release is longer time than the percutaneous radiofrequency ablation. Furthermore, the percutaneous radiofrequency ablation group had a shorter recovery time to normal activity than the open plantar fascia release group. There were no difference of postoperative VAS scores and the AOFAS-AH scores between the two groups. All patients reported satisfaction after either operation.

Conclusion: Symptoms of pain and limb function were significantly improved in patients both of the partial plantar fascia release treated group and the percutaneous radiofrequency ablation treated group. The two types of surgical procedures shared the same long-term curative effects. However, percutaneous radiofrequency ablation was a better technique from the point of shorter operative time and postoperative recovery time.

Trial registration: Retrospectively registered.

\section{Background}

Heel pain is one of the most common problems which patients seeking help in foot and ankle surgery clinic. Plantar fasciitis is one of the main pathologies in heel pain in adults and accounts for $11 \%$ to $15 \%$ of all foot diseases that require medical attention[1, 2]. Plantar fasciitis is more prevalent in sedentary individuals but also in athletes involving running sports[3].

The pathogenesis of plantar fasciitis is not clear. Lemont believed that plantar fasciitis was a pathological change dominated by metatarsal fascia degeneration[4]. Nery thought that heel pain was due to chronic strain of metatarsal fascia, which was secondary to aseptic inflammation caused by microtear caused by repeated microinjury[5]. Most of the patients were satisfied with the conservative treatment, such as traction stretching exercise, splinting, bracing, extracorporeal shock wave, oral administration of anti-inflammatory drugs no matter what the pathological changes were[6, 7]. Surgical interventions would be considered when patients with intractable plantar fasciitis showed nagative responses to over 6 months of conservative treatment $[8,9]$. There are many options for surgical 
treatment. Open surgery, endoscopic plantar fascia debridement, laser, platelet-rich plasma injection, radiofrequency ablation and other programs have achieved a certain degree of curative effect[10-13].

The plantar fascia release and percutaneous radiofrequency ablation used in this study belongs to minimally invasive surgery, but the difference between the two is not clear. here is a retrospective analysis which was carried out to compare the therapeutic effects of open plantar fascia release and percutaneous radiofrequency ablation in the treatment of in tractable plantar aponeurositis in order to pursue a better treatment of metatarsal fasciitis.

\section{Materials And Methods}

\section{Patients}

A retrospective analysis was carried out in intractable plantar fasciitis patients who received surgical treatment in the department of orthopedic surgery of our hospital during March 2009 to July 2018. Diagnosis of plantar fasciitis was made according to the guidelines described by McPoil for plantar fasciitis including tenderness in the plantar medial heel region on palpation, pain most noticeable with initial steps after a period of inactivity but also worse following prolonged weightbearing, and pain often precipitated by a recent increase in weightbearing activity[14].

\section{Inclusion criteria and exclusion criteria}

All the patients were chosen by the following criteria. The inclusion criteria were patients diagnosed with plantar fasciitis, with failure of conservative treatment for at least 6 months and patients without flat feet or gastrocnemius contracture. The exclusion criteria were patients with any previous history of surgery for heel pain, associated pathology involving the lower limb such as history of tarsal tunnel syndrome, effusion of the ankle indicating an intra-articular disease, Achilles tendinopathy, patients with systemic disorder like diabetes mellitus and rheumatoid arthritis and any recent history of aspirin or aspirin like drug intake.

With the inclusion criteria and exclusion criteria, 31 cases operated by a single doctor were selected. The patient chose the surgical procedure according to their own wishes after communicating with the doctor. Among the enrolled 31 cases, there were 16 patients (19 feet) received open plantar fascia release, and the other 15 patients (20 feet) received percutaneous radiofrequency ablation. All the included cases were confirmed to have plantar fasciitis clinically. All patients received and failed at least 6 months of conservative treatment including stretching traction training, splinting, bracing and extracorporeal shock wave.

\section{Surgical procedure}

1. Open plantar fascia release 
Patients who received open plantar fascia release were administered with sedation and regional block and placed in supine position. Patients were prepped and draped with standard routine iodine and alcohol and sterilized drapes. Tourniquet was used in 16 cases of patients (19 feet). $1 \mathrm{~cm}$ Medial incision of the heel was used. Dissection carried out through skin and subcutaneous tissue and exposed plantar fascia from medial hindfoot. Half of the medial plantar fascia was released (Fig 1, 2). Surgical wound was closed with suture following irrigation and covered with sterile dressings.

\section{Percutaneous radiofrequency ablation}

The maximum tenderness area of the affected side of the plantar fascia was identified preoperatively. Accordingly, marked the tenderness area with a medical marker in a grid pattern with $3 \mathrm{~mm}$ intervals of points covering the entire mapped out area. Standard routine iodine and alcohol disinfection of skin prep and sterilized draping was applied. Local infiltration anesthesia was conducted using $1 \%$ lidocaine at the peripheral of the marked region followed by subcutaneous injection of normal saline at the marked region. A $2 \mathrm{~mm}$ Kirschner wire was used as a puncture needle to puncture the skin and subcutaneous tissue at the marking points. Subsequently, a radio frequency cutter was inserted to the plantar fascia level at each puncture point of the marked grid and radiofrequency ablation was then performed percutaneously. Sterilized dressing was then applied locally at the end of the procedure (Fig 1,3).

\section{Post-procedure Protocol}

Local soft sterile dressings were applied for all the patients and left on for 2 weeks. The patients were allowed to do mild active stretching exercises for the plantar fascia and Achilles tendon with the protection of a brace. High-impact activities were forbidden for one month.

\section{Assessment}

Visual analogue scale (VAS) and American Orthopaedic Foot and Ankle Society Ankle-Hindfoot scale (AOFAS-AH) were adopted for assessment before and after surgery in all patients to evaluate the pain and lower limb function of the studied patients before and after operation. Sex, age, body mass index, duration of pain were also recorded. All patients were followed up for patient reported satisfaction rate with the curative effect of the procedures in outpatient visits at 1 month, 2 month, 3month, 12 month post operation and in July 2018 at the end of this study.

\section{Statistical analysis}

Both feet of the patients were analyzed using bilateral data analysis. SPSS 19.0 statistical software was used for statistical analysis. Continuous variables were presented as mean \pm standard deviation (SD) and statistically analyzed by Student's $t$ test with normal distribution. Non-normally distributed data was analyzed by Mann-Whitney $U$ rank sum test. A value of $P<0.05$ was considered as significant.

\section{Results}


From March 2009 to July 2018, a total of 31 cases (39 feet) of intractable plantar Fasciitis received surgical treatment. Among which, there were 16 cases of patients (19 feet) received open plantar fascia release, and the other 15 cases of patients (20 feet) received percutaneous radiofrequency ablation. There were 12 male and 19 female patients with a male-to-female ratio of 1: 1.58 . The average age of the enrolled 31 patients was 52.13 years old. 26 of the patients were at the age of $40-70$ years old. There was no differences of patients demographic Characteristics between two groups including ages, sex, body mass index (BMI) and duration of pain (Table 1). The average duration of the symptoms was 20.03 months (ranging from 6 to 120 months) in all patients. In addition, there were 18 cases of patients presented with calcaneal osteophytes. The average operative time was $36.78 \mathrm{~min}$ and $19.73 \mathrm{~min}$ in the open plantar fascia release and the percutaneous radiofrequency ablation respectively. The radiofrequency ablation group had a shorter mean operative time than the open group $(P=0.012)$. The average time that patients recovered to normal activity was 25.94 days in the plantar fascia open release group and 13.27 days in the percutaneous radiofrequency ablation group. The recovery time of the percutaneous radiofrequency ablation treated group was shorter than the open release group $(P=0.008)$ (Table 2). 
Table 1

Patients Demographics of the two groups.

\begin{tabular}{|c|c|c|c|}
\hline Viarable & $\begin{array}{l}\text { Open Plantar fascia } \\
\text { Release }\end{array}$ & $\begin{array}{l}\text { Percutaneous radiofrequency } \\
\text { ablation }\end{array}$ & $\begin{array}{l}P \\
\text { Value }\end{array}$ \\
\hline \multicolumn{4}{|l|}{ Age, y } \\
\hline $\begin{array}{l}\text { Mean } \pm \\
\text { SD }\end{array}$ & $49.63 \pm 9.78$ & $54.80 \pm 13.83$ & 0.236 \\
\hline Range & $25-65$ & $24-77$ & \\
\hline \multicolumn{4}{|l|}{ Sex, No. } \\
\hline Male & 6 & 6 & 0.891 \\
\hline Female & 10 & 9 & 0.891 \\
\hline \multicolumn{4}{|l|}{$\mathrm{BMl}, \mathrm{kg} / \mathrm{m} 2$} \\
\hline $\begin{array}{l}\text { Mean } \pm \\
\text { SD }\end{array}$ & $26.80 \pm 2.67$ & $26.27 \pm 3.03$ & 0.604 \\
\hline Range & $21.48-32.11$ & $21.72 \pm 32$ & \\
\hline \multicolumn{4}{|l|}{ Duration of pain, mo } \\
\hline $\begin{array}{l}\text { Mean } \pm \\
\text { SD }\end{array}$ & $22.75 \pm 30.97$ & $17.13 \pm 12.70$ & 0.878 \\
\hline Range & $6-120$ & $6-60$ & \\
\hline
\end{tabular}

Table 2

Operative time and recovery time of the two groups.

\begin{tabular}{|lll|}
\hline & Operative time (minutes) & Recovery time (days) \\
\hline Open Plantar fascia Release & $36.78 \pm 22.62$ & $25.94 \pm 15.47$ \\
\hline Percutaneous radiofrequency ablation & $19.93 . \pm 9.66$ & $13.27 \pm 7.48$ \\
\hline P value & 0.012 & 0.008 \\
\hline
\end{tabular}

The patients in the open plantar fascia release group reported a preoperative and postoperative mean VAS scores of $(8.81 \pm 1.11)$ and $(0.50 \pm 1.41)$ respectively with an average reduction of 8.31 points $(\mathrm{P}<$ $0.001)$; The patients in the percutaneous radiofrequency ablation group had a mean VAS scores ( $7.87 \pm$ $1.73)$ and $(0.73 \pm 1.28)$ preoperatively and postoperatively. The average reduction was 7.14 points $(P<$ 0.001) (Table 3). 
Table 3

VAS scores of the two groups.

\begin{tabular}{|llll|}
\hline & $\begin{array}{l}\text { Pre-oprative VAS } \\
\text { score }\end{array}$ & $\begin{array}{l}\text { Post-oprative VAS } \\
\text { score }\end{array}$ & P value \\
\hline Open Plantar fascia Release & $8.81 \pm 1.11$ & $0.50 \pm 1.41$ & 0.000 \\
\hline $\begin{array}{l}\text { Percutaneous radiofrequency } \\
\text { ablation }\end{array}$ & $7.87 \pm 1.73$ & $0.73 \pm 1.28$ & 0.000 \\
\hline P value & 0.078 & 0.634 & \\
\hline
\end{tabular}

AOFAS cares were also obtained in patients of the open release group with a mean AOFAS scores of (39.63 \pm 8.52$)$ and $(99.38 \pm 2.50)$ before and after operation. An average of 59.75 points $(P<0.001)$ increase was found; The mean AOFAS scores in the patients treated with percutaneous radiofrequency ablation were $(42.73 \pm 10.75)$ and $(98.40 \pm 4.24)$ before and after operation with an increase of average 56.67 points $(P<0.001)$ (Table 4$)$. There is no significant difference between the two groups in AOFAS points post-operatively in the follow-up.

Table 4

AOFAS scores of the two groups.

\begin{tabular}{|llll|}
\hline & $\begin{array}{l}\text { Pre-oprative AOFAS } \\
\text { score }\end{array}$ & $\begin{array}{l}\text { Post-oprative AOFAS } \\
\text { score }\end{array}$ & $\begin{array}{l}\text { P } \\
\text { value }\end{array}$ \\
\hline Open Plantar fascia Release & $39.63 \pm 8.52$ & $99.38 \pm 2.50$ & 0.000 \\
\hline $\begin{array}{l}\text { Percutaneous radiofrequency } \\
\text { ablation }\end{array}$ & $42.73 \pm 10.75$ & $98.40 \pm 4.24$ & 0.000 \\
\hline P value & 0.378 & 0.438 & \\
\hline
\end{tabular}

All 31 patients were followed up by telephone questionnaire and 29 patients were satisfied with the operation. Two patients with poor satisfaction were all in the open plantar fascia release group. In these two cases, 1 patient had a combined insertional Achilles tendinopathy. However, the plantar fascia pain was completely relieved after operation except for the pain of the Achilles tendinopathy; The other case had a flatfoot deformity before the procedure and sustained irritation of subtalar screw from other procedures of flat foot. No complications of infection, hematoma, complex regional pain syndrome occurred in all 31 patients.

\section{Discussion}

Heel pain is a general term of various diseases process affecting the daily work and life of patients. The etiologies are complicated and include plantar fasciitis, rupture of plantar fascia, calcaneal stress fracture, heel fat pad atrophy and or inflammation caused by strain and degeneration, retrocalcaneal 
bursitis, Achilles tendinitis, and irritation of calcaneal osteophytes formation. Many supports that plantar fasciitis is one of the main causes. Epidemiological studies show that plantar fasciitis is estimated to account for $11 \%-15 \%$ of all foot disease that require medical attention[15]. It is common in the elderly population aged from 40 to 70 years. Workers with long standing hours, runners and obese patients with BMI more than $30 \mathrm{~kg} / \mathrm{m}^{2}$ are the high-risk population with higher intensity of pain[16].

It is estimated that about $90 \%$ of patients with plantar fasciitis received conservative treatment with satisfactory effect, and no further surgical intervention were needed $[17,18]$. Therefore, the American Orthopedic Foot and Ankle Society recommends that patients diagnosed with plantar fasciitis should receive at least 6 months of conservative treatment before undergoing surgical intervention[8]. Conservative treatment methods include stretching traction training, splinting, bracing, extracorporeal shock wave, oral administration of drugs, and local injections of corticosteroid medications. Drug injection is also a common treatment for fasciitis. Rastega et al found that steroid injection could palliate plantar heel pain rapidly but dry needling can provide more satisfactory results for patients with plantar fasciitis in the long term in a random clinical trail.[19] PRP injection was associated with improved pain and function scores at three month follow-up when compared with corticosteroid injections[20, 21]. Polydeoxyribonucleotide was certificated as an effective and safe treatment option and may be considered for plantar fasciitis by Kim JK and Chung JY[22].

For patients with intractable plantar fasciitis failed at least 6 months of conservative treatment, surgical intervention can be considered. Open plantar fascia release is the most traditional operation method. According to the reports, the postoperative satisfaction rate of open release was 50\%-95\%[23, 24]. However, disadvantages of the surgery include large wound, longer postoperative recovery time, and potential postoperative occurrence of complex regional pain syndrome. Although plantar fascia release under arthroscopy has the advantage of minimally invasive, there are still postoperative complications mostly reported with incomplete pain-relieving occurring higher in rate than the traditional open plantar fascia release[24-27]. Xu reported a modified minimally invasive surgical system in open release of plantar fascia[28]. In this study, all of the patients in the open plantar fascia release were operated with this modified minimally invasive technique.

Bipolar radiofrequency ablation technique was first used in the treatment of cardiovascular disease to promote the regeneration of ischemic myocardium in patients with chronic heart failure[29-31]. Weil and his colleagues applied this technique for the treatment of intractable plantar fasciitis in the early stage with good results[32]. In a prospective study consisting of 21 cases in 2011, Sorensen et al. supported the curative effect of this type of technique; In the same year, Hormozi et al. also reported the therapeutic effect of this operation based on a prospective study of 14 cases[33, 34].

In this study, the average age of the enrolled 31 patients was 52.13 years old, among which, there were 26 patients at the age of $40-70$ years old accounting for $83.87 \%$ of the total subjects which was similar to the demographics reported from the previous investigations. There were 14 overweight patients $(24 \leq$ $\mathrm{BMI}<28)$ and 10 obese patients (BMI $\geq 28)$, accounting for $45.16 \%$ and $32.26 \%$ respectively. 
The results of this study showed a shorter average operation time of percutaneous radiofrequency ablation than the open plantar fascia release. We contribute this result to the relatively simple operation process of this method as reported also in the previous[33,34]. At the same time, the average recovery time was shorter in the percutaneous radiofrequency ablation group, and the result was also consistent with the previous literature[33]. Possible reasons might be that percutaneous radiofrequency ablation had relatively smaller individual wounds and thus retained the integrity of the plantar fascia[34]. There was no difference of postoperative VAS scores and the AOFAS-AH scores between the two groups, indicating that the two types of surgical procedures share the same curative effects. There were no major postoperative complications in both groups in our study.

Calcaneal osteophytes is also known as calcaneal spur. Many scholars believed that the calcaneal osteophytes is one of the major factors responsible for heel pain, and some scholars even described heel pain as calcaneal osteophytes syndrome[1]. Johal et al. in their study insisted that there was a positive correlation between calcaneal osteophytes and plantar fasciitis. However, the hypothesis was not able to explain the asymptomatic calcaneal osteophytes[35]. Kumai supported that calcaneal osteophytes was associated with the degeneration of cartilage cells at the insertion of the plantar fascia, regardless of the role of the traction of the plantar fascia[36]. In this study, there were 18 cases out of 31 had calcaneal osteophytes, of which only 1 case underwent intraoperative calcaneal osteophytes resection. All patients had significant improvement with pain postoperatively. We may speculated that there was no significant correlation between calcaneal osteophytes and the incidence of heel pain.

During the follow-up period, 29 patients were satisfied with the operation with a satisfaction rate of 93.55\%. Two patients reported poor clinical results. Among which, one patient had a combined Achilles tendinopathy. The pain from plantar fascia pain was completely relieved after operation while there was still pain of the Achilles tendinopathy; The other patient had a flatfoot deformity treated before the plantar fascia operation. The irritation of the subtalar tarsal screw remained after our intervention of the plantar fascia. However, heel pain symptoms and limb function were both improved in the two patients after plantar fasicia operation.

With the design limitation of a retrospective study, our results could be affected by various factors, such as selection bias, small sample size, and lack of long-term follow-up period. Small sample size is common in many of the available reports. We believe that the results of this study will be helpful for relevant design of prospective studies in the future.

Collectively, based on the experiences in the treatment of 31 patients with intractable plantar fasciitis, we believe that open plantar fascia release and percutaneous radiofrequency ablation can significantly relief the pain and improve limb function in patients with intractable plantar fasciitis. Percutaneous radiofrequency ablation has shown the advantages of shorter operation time, shorter postoperative recovery time, higher postoperative function scores and therefore may be a better option while selecting surgical interventions of the intractable plantar fasciitis. 


\section{Conclusion}

The observations made in the present study suggest that the treatment of plantar fasciitis with plantar fascia lysis or percutaneous radiofrequency ablation is equally effective. The technique of percutaneous radiofrequency ablation can shorten the operative time and postoperative recovery time.

\section{Abbreviations}

VAS: Visual analogue scale; AOFAS-AH: American Orthopaedic Foot and Ankle Society Ankle-Hindfoot scale; BMI: Body mass index.

\section{Declarations}

Acknowledgements

Not applicable.

\section{Authors' contributions}

XHL designed the study. And all surgeries were performed by XHL, LH, QY, and XYB. YYS and QY completed the draft of the manuscript. YYS was responsible for data analysis. YYS and QY contributed to data collection and outcomes evaluation. All authors read and approved the final manuscript.

\section{Funding}

The current study received Beijing Municipal Science and Technology Project (No. Z181100001718159); National Key Research and Development Program of China (No. 2016YFC1101604); the Ministry of Education Innovation Program of China (No. IRT_16R01).

\section{Availability of data and materials}

All datasets used during the current study are available from the corresponding author on reasonable request.

\section{Ethics approval and consent to participate}

Not applicable. 


\section{Consent for publication}

Not applicable.

\section{Competing interests}

The authors declare that they have no competing interests.

\section{References}

1. Lane GD, London B. Heel spur syndrome: a retrospective report on the percutaneous plantar transverse incisional approach. J Foot Ankle Surg. 2004;43:389-394.

2. Jain SK, Suprashant K, Kumar S, Yadav A, Kearns SR. Comparison of Plantar Fasciitis Injected With Platelet-Rich Plasma vs Corticosteroids. Foot Ankle Int. 2018;39:780-786.

3. Trojian T, Tucker AK. Plantar Fasciitis. Am Fam Physician. 2019;99:744-750.

4. Lemont $\mathrm{H}$, Ammirati KM, Usen N. Plantar fasciitis: a degenerative process (fasciosis) without inflammation. J Am Podiatr Med Assoc. 2003;93:234-237

5. Nery C, Raduan F, Mansur N, Baunfeld D, Del Buono A, Maffulli N. Endoscopic approach for plantar fasciopathy: a long-term retrospective study. Int Orthop. 2013;37:1151-1156.

6. Banerjee R, Chao JC, Taylor R, Siddiqui A. Management of calcaneal tuberosity fractures. J Am Acad Orthop Surg. 2012;20:253-258.

7. DiGiovanni BF, Moore AM, Zlotnicki JP, Pinney SJ. Preferred management of recalcitrant plantar fasciitis among orthopaedic foot and ankle surgeons. Foot Ankle Int. 2012;33:507-512.

8. Luffy L, Grosel J, Thomas R, So E. Plantar fasciitis: A review of treatments. JAAPA. 2018;31:20-24.

9. Johnson RE, Haas K, Lindow K, Shields R. Plantar fasciitis: what is the diagnosis and treatment? Orthop Nurs. 2014;33:198-204: quiz 205-196.

10. Cottom JM, Baker JS. Endoscopic Plantar Fascia Debridement for Chronic Plantar Fasciitis. Clin Podiatr Med Surg. 2016;33:545-551.

11. Franceschi F, Papalia R, Franceschetti E, Paciotti M, Maffulli N, Denaro V. Platelet-rich plasma injections for chronic plantar fasciopathy: a systematic review. Br Med Bull. 2014;112:83-95.

12. Ordahan B, Karahan AY, Kaydok $E$. The effect of high-intensity versus low-level laser therapy in the management of plantar fasciitis: a randomized clinical trial. Lasers Med Sci. 2018;33:1363-1369.

13. Chou AC, Ng SY, Su DH, Singh IR, Koo K. Radiofrequency microtenotomy is as effective as plantar fasciotomy in the treatment of recalcitrant plantar fasciitis. Foot Ankle Surg. 2016;22:270-273.

14. McPoil TG, Martin RL, Cornwall MW, Wukich DK, Irrgang JJ, Godges JJ. Heel pain-plantar fasciitis: clinical practice guildelines linked to the international classification of function, disability, and health 
from the orthopaedic section of the American Physical Therapy Association. J Orthop Sports Phys Ther. 2008;38:A1-A18.

15. League AC. Current concepts review: plantar fasciitis. Foot Ankle Int. 2008;29:358-366.

16. Riddle DL, Pulisic M, Pidcoe P, Johnson RE. Risk factors for Plantar fasciitis: a matched case-control study. J Bone Joint Surg Am. 2003;85:872-877.

17. Martin RL, Irrgang JJ, Conti SF. Outcome study of subjects with insertional plantar fasciitis. Foot Ankle Int. 1998;19:803-811.

18. Riddle DL, Schappert SM. Volume of ambulatory care visits and patterns of care for patients diagnosed with plantar fasciitis: a national study of medical doctors. Foot Ankle Int. 2004;25:303310.

19. Rastegar S, Baradaran Mahdavi S, Hoseinzadeh B, Badiei S. Comparison of dry needling and steroid injection in the treatment of plantar fasciitis: a single-blind randomized clinical trial. Int Orthop. 2018;42(1):109-116.

20. Singh P, Madanipour S, Bhamra JS, Gill I. A systematic review and meta-analysis of platelet-rich plasma versus corticosteroid injections for plantar fasciopathy. Int Orthop. 2017;41(6):1169-1181.

21. Zhang H, Xiao T. Comment on Singh et al::A systematic review and meta-analysis of platelet-rich plasma versus corticosteroid injections for plantar fasciopathy. Int Orthop. 2018;42(1):219-220.

22. Kim JK, Chung JY. Effectiveness of polydeoxyribonucleotide injection versus normal saline injection for treatment of chronic plantar fasciitis: a prospective randomised clinical trial. Int Orthop. 2015;39(7):1329-34.

23. 23. Cole C, Seto C, Gazewood J. Plantar fasciitis: evidence-based review of diagnosis and therapy. Am Fam Physician. 2005;72:2237-2242.

24. 24. Davies MS, Weiss GA, Saxby TS. Plantar fasciitis: how successful is surgical intervention? Foot Ankle Int. 1999;20:803-807.

25. 25. Bazaz R, Ferkel RD. Results of endoscopic plantar fascia release. Foot Ankle Int. 2007;28:549556. 26. Kinley S, Frascone S, Calderone D, Wertheimer SJ, Squire MA, Wiseman FA. Endoscopic plantar fasciotomy versus traditional heel spur surgery: a prospective study. J Foot Ankle Surg. 1993;32:595-603.

26. 27. Saxena A. Uniportal endoscopic plantar fasciotomy: a prospective study on athletic patients. Foot Ankle Int. 2004;25:882-889.

27. 28. Xu HL, Xu L, Zhang DY, Fu ZG, Wang TB, Zhang PX, Jiang BG. Minimally invasive treatment of the KobyGard system for plantar fasciitis: a retrospective study. Chin Med J (Engl). 2012;125:39663971.

28. 2 Fisher PE, Khomoto T, DeRosa CM, Spotnitz HM, Smith CR, Burkhoff D. Histologic analysis of transmyocardial channels: comparison of $\mathrm{CO} 2$ and holmium:YAG lasers. Ann Thorac Surg. 1997;64:466-472. 
29. 30. Kwon HM, Hong BK, Jang GJ, Kim DS, Choi EY, Kim IJ, McKenna CJ, Ritman EL, Schwartz RS. Percutaneous transmyocardial revascularization induces angiogenesis: a histologic and 3dimensional micro computed tomography study. J Korean Med Sci. 1999;14:502-510.

30. 31. Dietz U, Horstick G, Manke T, Otto M, Eick O, Kirkpatrick CJ, Meyer J, Darius H. Myocardial angiogenesis resulting in functional communications with the left cavity induced by intramyocardial high-frequency ablation: histomorphology of immediate and long-term effects in pigs. Cardiology. 200399:32-38.

31. 32. Weil L, Jr., Glover JP, Weil LS, Sr.. A new minimally invasive technique for treating plantar fasciosis using bipolar radiofrequency: a prospective analysis. Foot Ankle Spec. 2008;1:13-18.

32. 33. Hormozi J, Lee S, Hong DK. Minimal invasive percutaneous bipolar radiofrequency for plantar fasciotomy: a retrospective study. J Foot Ankle Surg. 2011;50:283-286.

33. 34. Sorensen MD, Hyer CF, Philbin TM. Percutaneous bipolar radiofrequency microdebridement for recalcitrant proximal plantar fasciosis. J Foot Ankle Surg. 2011;50:165-170.

34. 35. Johal KS, Milner SA. Plantar fasciitis and the calcaneal spur: Fact or fiction? Foot Ankle Surg. 2012;18:39-41.

35. Kumai T, Benjamin M. Heel spur formation and the subcalcaneal enthesis of the plantar fascia. J Rheumatol. 2002;29:1957-1964.

\section{Figures}

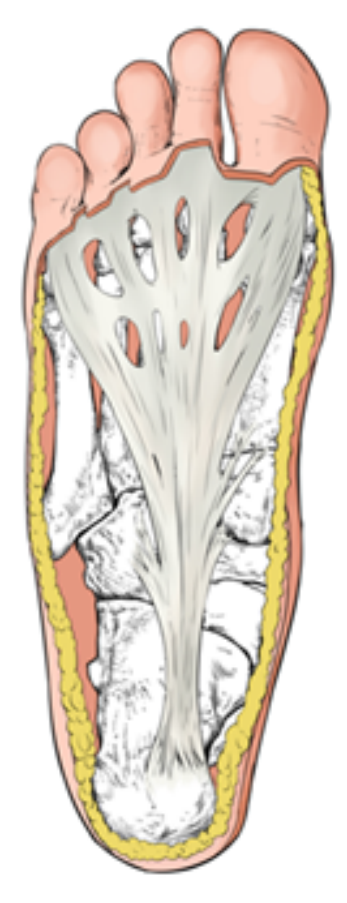

a

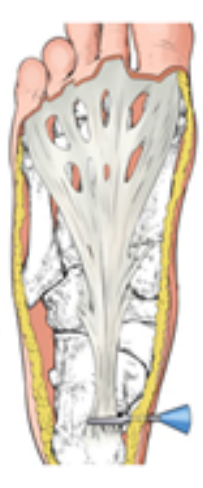

b 1

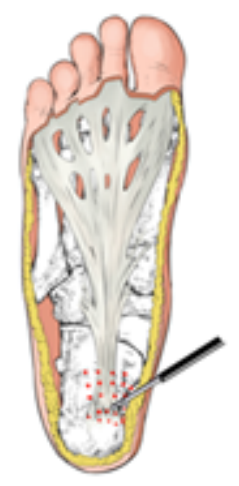

c 1

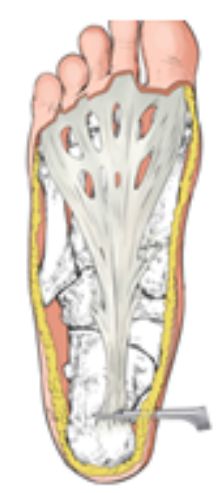

b 2

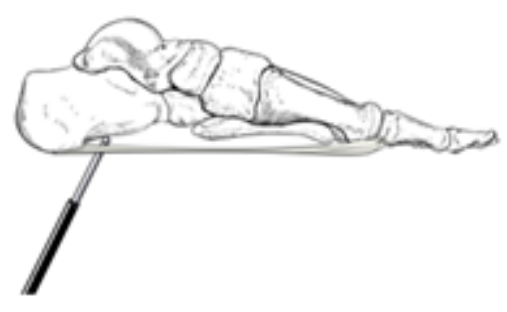

c 2 


\section{Figure 1}

Figure $a$ is an anatomical view of the tendon fascia. Figure $b$ is a schematic view of percutaneous fascia fascia surgery, and b1 shows the separation of the fascia fascia with a stent. B2 indicates that the iridium fascia is cut by $1 / 2$ along the stent groove with a blade. Figure $C$ is the surgical intent of radiofrequency ablation. The red dot in $\mathrm{c} 1$ is the position at which the ablation needle is inserted, and c2 is the depth at which the ablation needle is inserted.
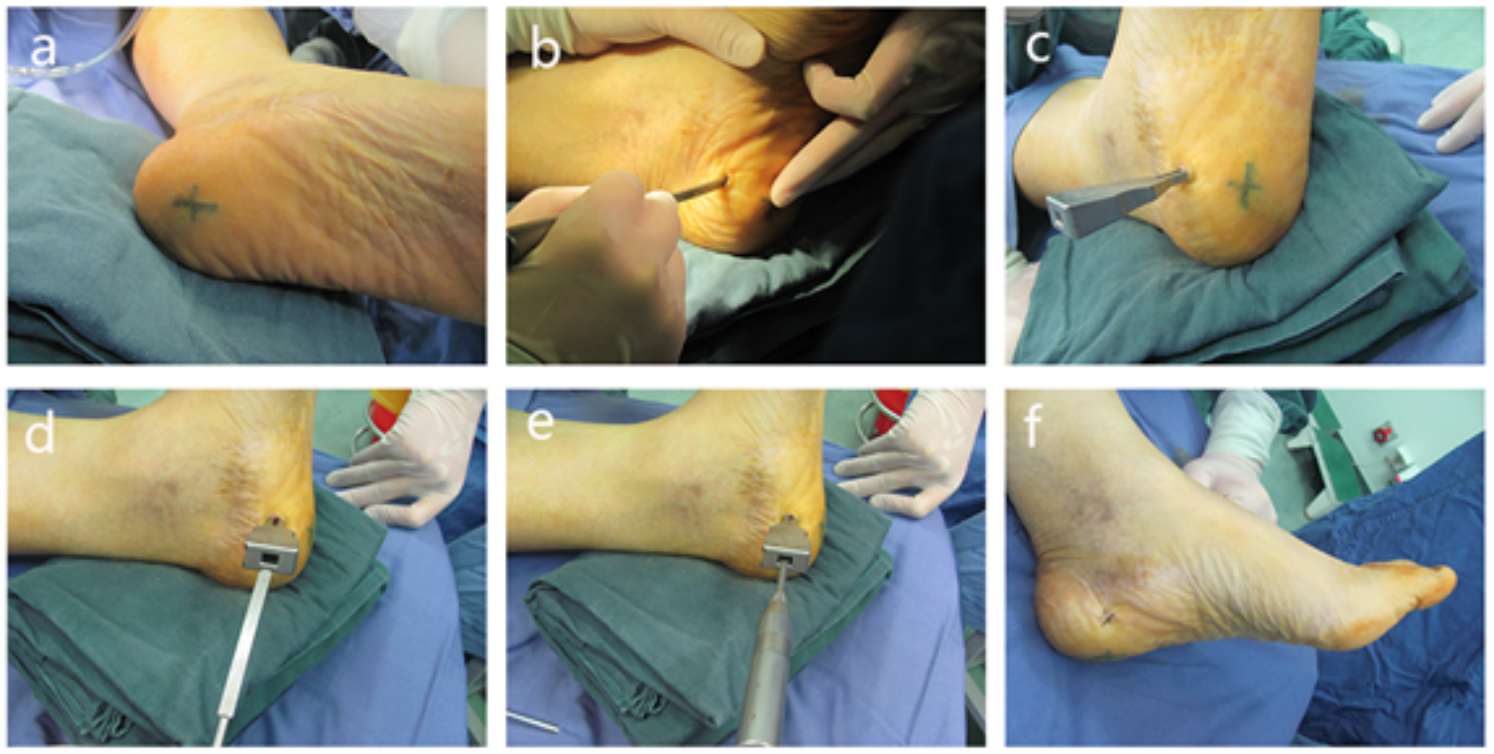

\section{Figure 2}

This figure shows the procedure of open plantar fascia release. (a) We marked the pain zone at first. (b-f) Dissection carried out through skin and subcutaneous tissue and exposed plantar fascia from medial hindfoot. Half of the medial plantar fascia was released through medial incision. (e) There was only a micro wound left on the foot. 

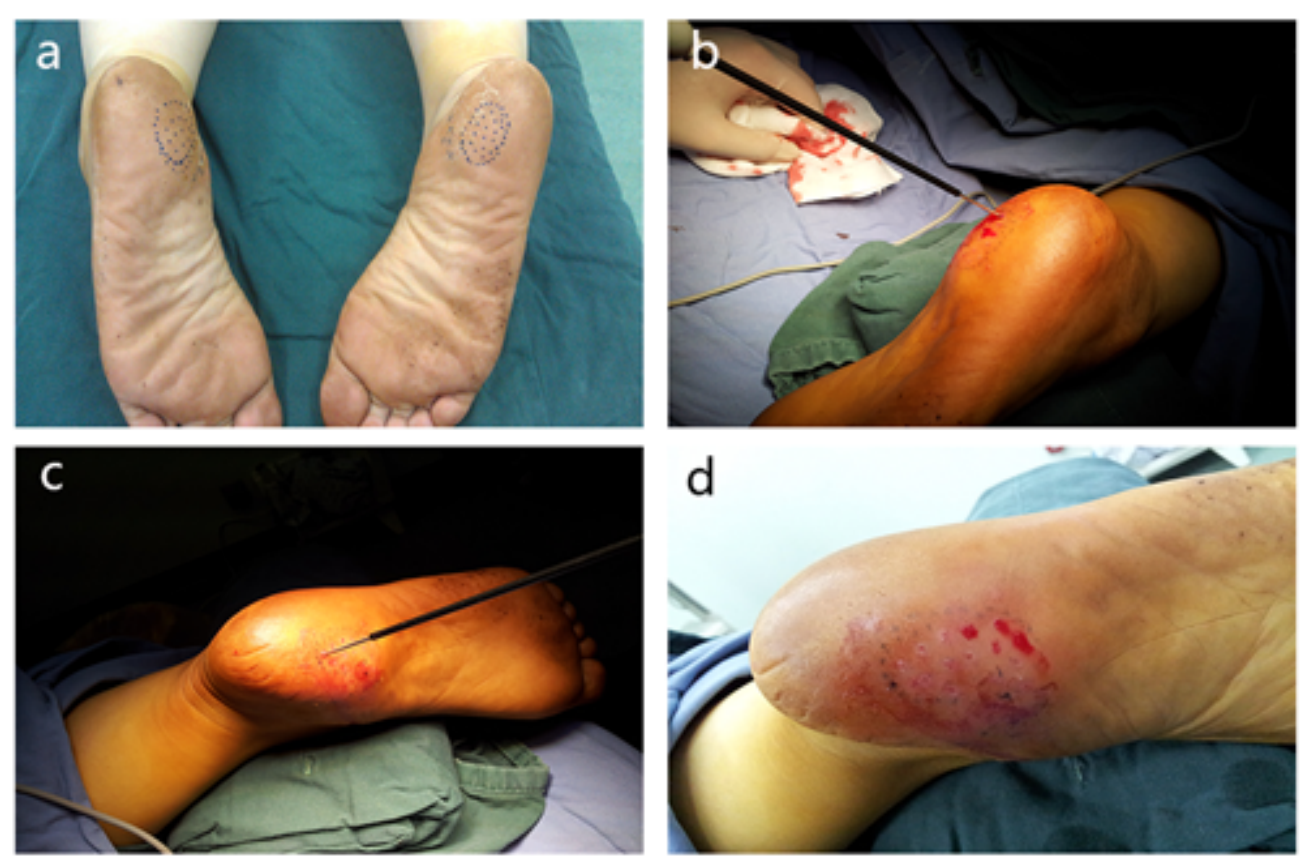

\section{Figure 3}

This figure shows the procedure of percutaneous radiofrequency ablation. (a) We marked the pain zone the at first. (b-c) A $2 \mathrm{~mm}$ Kirschner wire was used as a puncture needle to puncture the skin and subcutaneous tissue at the marking points. Subsequently, a radio frequency cutter was inserted to the plantar fascia level at each puncture point of the marked grid and radiofrequency ablation was then performed percutaneously. (d) There was no obvious wound after operation. 